\title{
Las facultades de documentación 2.0: El caso español ${ }^{1}$
}

\author{
Juan Carlos Villanueva Mateo \\ Lorena Martínez Solís ${ }^{2}$ \\ Universidad de Murcia - UM, España
}

ANALISE

\section{Resumen}

El presente trabajo analiza el uso que las facultades de documentación españolas hacen de las redes sociales a la hora de compartir contenidos con sus estudiantes, ya sean reales o potenciales. Los resultados obtenidos permiten observar que en general no hay un uso demasiado profuso de las herramientas 2.0, y que los centros de enseñanza que sí las utilizan suelen decantarse por la aplicación Facebook.

Palabras clave

Facultades de documentación ; Biblioteconomía y documentación ; Información y documentación ; Educación superior ; Redes sociales ; Difusión de contenidos

\section{Library and Information Science faculties 2.0: the spanish case}

Abstract

This paper analyzes the use made of social networking sites by Spanish Library and Information Science Faculties when sharing content with their students, whether actual or potential. The results obtained showed that overall there isn't too much use of Web 2.0 tools and educational establishments that use them tend to opt for Facebook.

Keywords

Library and Information Science Faculties ; Library and Information Science ; Higher education ; Social networks ; Dissemination of content

\section{Introducción y objetivos}

Castelló Martínez (2010) afirma que compartir, comunicar, conversar y cooperar son las 4 Cs de la web 2.0, que por medio de espacios y herramientas como los blogs, las redes sociales online, las plataformas de vídeo digital, las websites de intercambio de noticias ${ }^{3}$, las wikis, los marcadores sociales ${ }^{4}$, la sindicación ${ }^{5}$ o el microblogging ${ }^{6}$, han permitido al usuario generar contenidos, editarlos según sus intereses y compartirlos con su comunidad. Desde el lado de la organización, escuchar y relacionarse con los usuarios a través de estos nuevos espacios supone una transformación total de la cultura y la comunicación institucional.

Estos espacios virtuales permiten a las organizaciones participar en conversaciones y aportar contenido de interés para los usuarios, en un entorno favorable tanto para esos "seguidores" como para las instituciones que difunden la información. La creación de comunidades en torno a la marca o la imagen corporativa en lugares digitales como las redes sociales online facilita la construcción de branding ${ }^{7}$, además de servir como canal de fidelización. (Castelló Martínez, 2010). 
Como afirma Aranburu (2011), se puede decir que una de las labores divulgativas de las instituciones, en este estudio serán las Universidades, consiste en crear una oferta atractiva para que llegue al máximo número de personas. Para ello se utilizan soportes como folletos, mailings, medios de comunicación y las páginas web. Las redes sociales son un soporte más para hacer llegar la oferta de la organización a los usuarios. Se debe ver a estas herramientas electrónicas como un punto más donde se da a conocer la oferta de servicios y se debe pensar que Internet, como el papel, puede tomar diferentes formas, bien sea en una red social, blog, página web, etc., dependiendo del objetivo que se quiera conseguir.

Teniendo en cuenta este marco conceptual, nuestros objetivos son:

1. Localizar y seleccionar la muestra de estudio, que de manera específica estará compuesta por aquellas universidades/facultades españolas en las que se imparten titulaciones relacionadas con Información y Documentación, en concreto: la Diplomatura en Biblioteconomía y Documentación, la Licenciatura en Documentación, y el Grado en Información y Documentación;

2. Buscar y escoger las redes sociales más utilizadas en España;

3. Observar qué instituciones académicas de las pertenecientes a la muestra, disponen de todas o algunas de las aplicaciones escogidas en el paso anterior; y

4. Realizar un análisis comparativo de los centros de enseñanza que sí dispongan de alguna de las herramientas 2.0 citadas.

\section{Breve estado de la cuestión}

Caldevilla Domínguez (2010) indica que las redes sociales forman parte de la web $2.0^{8}$ y nacen como una reunión de personas, conocidas o desconocidas, que interactúan entre sí, redefiniendo al grupo y retroalimentándolo.

El mismo autor (2010) comenta, además, que la joven historia de las aplicaciones sociales tiene su comienzo en la crisis informática del año 2003, cuando casi todas las empresas que habían crecido al alimón de los mercados financieros se declararon en quiebra y cerraron sus portales de Internet por la falta de visitas. Fueron entonces los usuarios los que cobraron protagonismo, inspirados en la mensajería instantánea y en la proliferación de los foros de discusión. Algunos de los acontecimientos más importantes relacionados con las redes sociales desde esa fecha, han sido, según la página web Techsip (2012):

2003:

- Google compra Blogger.

- Linkedln lanza su red social para profesionales.

- Se crea Facebook para estudiantes de Harvard.

2004:

- MySpace supera a Friendster en páginas consultadas.

2005:

- News Corp compra MySpace por 580 millones de dólares.

- YouTube comienza a almacenar vídeos.

- MySpace se convierte en la red social más popular de Estados Unidos. 
2006:

- Google alcanza 400 millones de búsquedas al día.

- Nace Twitter.

2007:

- Facebook supera a MySpace en términos de visitas únicas mensuales.

2008:

- Facebook se convierte en la red social más utilizada en todo el mundo, con más de 200 millones de usuarios, duplicando el tráfico de visitas de MySpace.

2009:

- Facebook consigue más de 400 millones de usuarios, superando el tráfico semanal de Google.

- La popularidad de MySpace decae hasta los 57 millones de usuarios.

2010:

- Se estima la población de Internet en 1.97 billones de usuarios, cerca del 30\% de la población mundial. Internet supera a los periódicos como principal fuente de información para los americanos.

- Hay más de 550 millones de personas en Facebook, se envían 65 millones de tweets a través Twitter cada día, y 2 billones de vídeos son reproducidos en YouTube.

- $\quad$ Linkedln alcanza los 90 millones de usuarios profesionales.

2011:

- Facebook obtiene ingresos de 3.7 billones de dólares anualmente.

- Linkedln es la segunda red social más importante en los Estados Unidos con 33.9 millones de visitantes únicos al mes.

- $\quad$ Twitter envía 33 billones de tweets al día.

- Se lanza Google+.

2012 (primavera):

- Facebook planea vender acciones valorando la compañía entre los 75 y los 100 billones.

- Twitter alcanza los 12.233 tweets por segundo durante la Super Bowl.

Las palabras clave que mejor representan y definen el concepto de red social según Caldevilla Domínguez (2010), son:

1. Interactividad: ingentes cantidades de datos se transmiten en todo el planeta gracias a la tecnología. Como consecuencia, se producen intercambios de información simultáneos en todo el globo de manera casi instantánea.

2. Personalización: las redes sociales permiten tener un mayor control sobre qué información queremos recibir, destacar y compartir.

3. Capacidad Multimedia: la innovadora forma de interacción de la redes sociales, comparada con la navegación de tan sólo hace unos años y combinada con los nuevos 
formatos digitales (que nutren un ambiente descentralizado y no jerárquico dirigido por los nuevos usuarios), hacen que el uso de Internet haya adquirido nuevas dimensiones y metas.

4. Multiedición y retroalimentación: estas dos características definitorias de las redes sociales están ligadas sin duda alguna a la primera descrita: la interactividad. La tendencia actual es que los contenidos publicados en Internet no se conciban sólo para ser leídos y olvidados.

5. Revolución lingüística y legal: la falta de jurisdicción y normativa reguladora de las nuevas tecnologías hace del medio un lugar con un código propio en el que impera el sentido común y la inteligencia colectiva pero, que por desgracia, también es susceptible de ser injusto, amenazante o perjudicial. Por supuesto, en la mayoría de los casos, los usuarios son moderadores de sus propias opiniones y actuaciones y muchas publicaciones y webs renuncian a responsabilizarse de los contenidos emitidos por terceros, pero convienen en la necesidad de una normativa para expulsar o expedientar al internauta que obró de mala fe.

Como afirma Radillo (2010), hasta finales de los años noventa las organizaciones, públicas o privadas, que migraban a Internet no eran conscientes de las conversaciones online que sus públicos llevaban a cabo, es decir, "no los escuchaban". Según Cobo (2011), el advenimiento de la web 2.0 y la explosión de los medios sociales en Internet como herramientas de comunicación, atrajeron el interés de las personas.

Jessica Judex (2010), de la Agencia UM (Colombia), comenta que "así como hace ocho o diez años era indispensable para un negocio, u organización, tener una página web, hoy lo es el tener un papel activo en una red social. La ausencia de una institución, o imagen de una corporativa, en estas comunidades es como decirle a un consumidor, o usuario: 'gracias, pero no quiero saber su opinión de mí'”. (Citado por COBOS, T. L., 2011).

Por otro lado, y como bien indica Castelló Martínez (2010), Internet, con una audiencia mensual de más del 50\% de la población española y una inversión publicitaria de casi el 12\%, se ha convertido para muchas organizaciones en el medio idóneo para personalizar su mensaje, interactuar con el destinatario y satisfacer así las expectativas como clientes o usuarios. Afinidad con el público objetivo, generación de notoriedad con costes reducidos, segmentación y medición en tiempo real, son algunas de las ventajas del medio más alabadas por las instituciones, en el caso de este trabajo, por las Universidades.

Acerca del uso y utilidad de las redes sociales en el ámbito educativo, la revista Edutec-e. Revista Electrónica de Tecnología Educativa, en su número 43 de 2013, recoge varios trabajos en este sentido ${ }^{9}$. Destacan sobre todo los de Álvarez y López, Egaña, Bidegain y Zuberogoitia, y López Meneses, Llorent García y Fernández Márquez.

Asimismo, destaca el artículo de Esteve Mon y Gisbert Cervet (2011) en el que proponen que la universidad, bajo el marco del Espacio Europeo de Educación Superior, replantee su modelo educativo, impulsando y estimulando la educación activa del estudiante, a través de las TIC. Herramientas que, según los autores, facilitan los procesos de administración y gestión, la transmisión de los contenidos de estudio, y la alfabetización digital del alumnado.

Finalmente, cabe destacar que España es el primer país europeo y el segundo del mundo, tras Brasil, en porcentaje de internautas que participan en una de las principales herramientas de la web 2.0: las redes sociales online. Con casi 500 millones de usuarios, Facebook es a día de hoy la red social de más éxito, también entre las organizaciones, seguida de otras como MySpace, Tuenti o Linkedln. (Castelló Martínez, 2010).

Así pues, teniendo en cuenta las posibilidades que ofrecen las redes sociales a priori, como se ha indicado en los objetivos, vamos a observar el uso que hacen las facultades en las que se imparten titulaciones relacionadas con Información y Documentación de estas aplicaciones 2.0.

\section{Metodología}

Para llevar a cabo nuestra investigación el primer paso fue localizar y seleccionar la muestra de estudio, es decir, las universidades/facultades españolas en las que se imparten titulaciones relacionadas con Información y 
Documentación, en concreto: la Diplomatura en Biblioteconomía y Documentación, la Licenciatura en Documentación, y el Grado en Información y Documentación.

Tras realizar una búsqueda exhaustiva en la página "Universidades españolas" del Ministerio de Cultura ${ }^{10}$, y con los resultados obtenidos, se confeccionó un listado en el que, como se puede observar, aparece el nombre de la Universidad seguido de la facultad y/o escuela en la que se imparte algunos de los estudios de grado citados anteriormente (tabla 1):

\begin{tabular}{|c|c|c|}
\hline Universidad & Facultad & $\begin{array}{c}\text { Titulación/Titulaciones } \\
\text { (que imparte del área de: INF. Y DOC.) }\end{array}$ \\
\hline Universidad Abierta de Cataluña & $\begin{array}{l}\text { Facultad de Ciencias de la Información y de la } \\
\text { Comunicación }\end{array}$ & Grado en Información y Documentación \\
\hline $\begin{array}{l}\text { Universidad Autónoma de } \\
\text { Barcelona }\end{array}$ & Facultad de Ciencias de la Comunicación & Licenciatura en Documentación \\
\hline \multirow{3}{*}{ Universidad Carlos III } & \multirow{3}{*}{$\begin{array}{l}\text { Facultad de Humanidades, Comunicación y } \\
\text { Documentación }\end{array}$} & $\begin{array}{l}\text { Diplomatura en Biblioteconomía y } \\
\text { Documentación }\end{array}$ \\
\hline & & Licenciatura en Documentación \\
\hline & & Grado en Información y Documentación \\
\hline \multirow{3}{*}{$\begin{array}{l}\text { Universidad Complutense de } \\
\text { Madrid }\end{array}$} & \multirow{3}{*}{ Facultad de Ciencias de la Documentación } & $\begin{array}{l}\text { Diplomatura en Biblioteconomía y } \\
\text { Documentación }\end{array}$ \\
\hline & & Licenciatura en Documentación \\
\hline & & Grado en Información y Documentación \\
\hline \multirow{2}{*}{ Universidad de Alcalá } & \multirow{2}{*}{ Facultad de Documentación } & Licenciatura en Documentación \\
\hline & & Grado en Información y Documentación \\
\hline \multirow{3}{*}{ Universidad de Barcelona } & \multirow{3}{*}{ Facultad de Biblioteconomía y Documentación } & $\begin{array}{l}\text { Diplomatura en Biblioteconomía y } \\
\text { Documentación }\end{array}$ \\
\hline & & Licenciatura en Documentación \\
\hline & & Grado en Información y Documentación \\
\hline \multirow{3}{*}{ Universidad de Extremadura } & \multirow{3}{*}{$\begin{array}{l}\text { Facultad de Biblioteconomía y } \\
\text { Documentación11 }\end{array}$} & $\begin{array}{l}\text { Diplomatura en Biblioteconomía y } \\
\text { Documentación }\end{array}$ \\
\hline & & Licenciatura en Documentación \\
\hline & & Grado en Información y Documentación \\
\hline \multirow{3}{*}{ Universidad de Granada } & \multirow{3}{*}{ Facultad de Comunicación y Documentación } & $\begin{array}{l}\text { Diplomatura en Biblioteconomía y } \\
\text { Documentación }\end{array}$ \\
\hline & & Licenciatura en Documentación \\
\hline & & Grado en Información y Documentación \\
\hline
\end{tabular}

Tabla 1 (Continua) - Facultades de universidades españolas que imparten titulaciones relacionadas con Información y Documentación. Fuente: Elaboración propia a partir de la información de la página web Universidades españolas, del Ministerio de Cultura. Recuperado de http://goo.gl/Pfd1X. 


\begin{tabular}{|c|c|c|}
\hline Universidad & Facultad & $\begin{array}{l}\text { Titulación/Titulaciones } \\
\text { (que imparte del área de: INF. Y DOC.) }\end{array}$ \\
\hline \multirow{3}{*}{ Universidad de La Coruña } & \multirow{3}{*}{ Facultad de Humanidades } & $\begin{array}{l}\text { Diplomatura en Biblioteconomía y } \\
\text { Documentación }\end{array}$ \\
\hline & & Licenciatura en Documentación \\
\hline & & Grado en Información y Documentación \\
\hline \multirow[t]{2}{*}{ Universidad de León } & \multirow[t]{2}{*}{ Facultad de Filosofía y Letras } & $\begin{array}{l}\text { Diplomatura en Biblioteconomía y } \\
\text { Documentación }\end{array}$ \\
\hline & & Grado en Información y Documentación \\
\hline \multirow{3}{*}{ Universidad de Murcia } & \multirow{3}{*}{ Facultad de Comunicación y Documentación } & $\begin{array}{l}\text { Diplomatura en Biblioteconomía y } \\
\text { Documentación }\end{array}$ \\
\hline & & Licenciatura en Documentación \\
\hline & & Grado en Información y Documentación \\
\hline \multirow{3}{*}{ Universidad de Salamanca } & \multirow{3}{*}{ Facultad de Traducción y Documentación } & $\begin{array}{l}\text { Diplomatura en Biblioteconomía y } \\
\text { Documentación }\end{array}$ \\
\hline & & Licenciatura en Documentación \\
\hline & & Grado en Información y Documentación \\
\hline \multirow[t]{2}{*}{ Universidad de Valencia } & \multirow[t]{2}{*}{ Facultad de Geografía e Historia } & $\begin{array}{l}\text { Diplomatura en Biblioteconomía y } \\
\text { Documentación }\end{array}$ \\
\hline & & Grado en Información y Documentación \\
\hline Universidad de Vic & $\begin{array}{l}\text { Facultad de Educación, Traducción y Ciencias } \\
\text { Humanas }\end{array}$ & $\begin{array}{l}\text { Diplomatura en Biblioteconomía y } \\
\text { Documentación }\end{array}$ \\
\hline \multirow[t]{2}{*}{ Universidad de Zaragoza } & \multirow[t]{2}{*}{ Facultad de Filosofía y Letras } & $\begin{array}{l}\text { Diplomatura en Biblioteconomía y } \\
\text { Documentación }\end{array}$ \\
\hline & & Grado en Información y Documentación \\
\hline $\begin{array}{l}\text { Universidad Politécnica de } \\
\text { Valencia }\end{array}$ & $\begin{array}{l}\text { Escuela Técnica Superior de Ingeniería } \\
\text { Informática }\end{array}$ & Licenciatura en Documentación \\
\hline
\end{tabular}

Tabla 2 (Conclusión) - Facultades de universidades españolas que imparten titulaciones relacionadas con Información y Documentación. Fuente: Elaboración propia a partir de la información de la página web Universidades españolas, del Ministerio de Cultura. Recuperado de http://goo.gl/Pfd1X.

Una vez escogida la muestra de estudio, el siguiente paso fue el de seleccionar las redes sociales a través de las cuales se iba a observar cómo las facultades realizaban la gestión de sus contenidos.

Teniendo en cuenta que son muchas las aplicaciones 2.0 de este tipo disponibles actualmente a través de Internet y que su estudio, por tanto, iba a ser inabarcable, se decidió analizar aquellas más utilizadas. Para ello, en primer lugar se tuvo en cuenta el estudio realizado en 2010 por Discapnet, denominado "Accesibilidad de Plataformas de Redes Sociales", en el que se recoge el ranking de sitios web más visitados elaborado por la página web Alexa.com ${ }^{12}$. 
En el citado trabajo se determina que:

No existen datos fiables sobre el número de usuarios de las diferentes plataformas (en muchos casos ni siquiera las propias plataformas proporcionan esta información), y además estas cifras varían constantemente. En este caso se ha tomado como referencia el ranking de sitios web más visitados que elabora Alexa.com, según el cual en España las plataformas de redes sociales más visitadas son, en este orden, Facebook, Tuenti, Twitter, Flickr y LinkedIn.

Seguidamente se consultó el informe realizado en 2011 por The Cocktail Analysis. En este trabajo se determinó que las redes sociales con un índice mayor de acceso desde dispositivos móviles, siendo estudiadas sobre el número de usuarios totales de esa red, eran las mismas que en el caso anterior (figura 1):

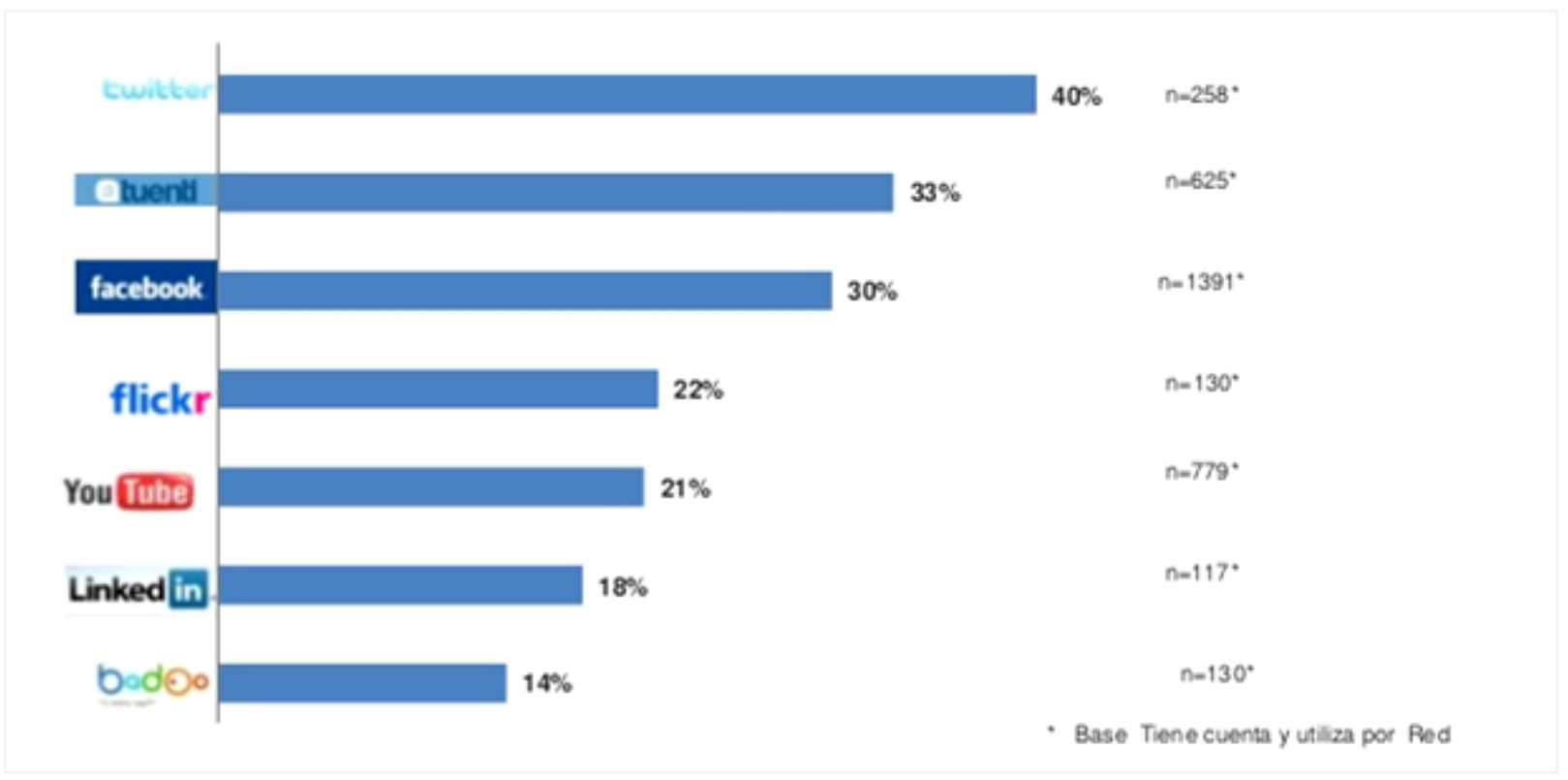

Figura 1 - Ranking de redes sociales más utilizadas en 2011. Fuente: Cocktail Analysis, The. (2011). Informe de resultados. Observatorio de redes sociales: tercera oleada. Diapositiva 48. Recuperado de http://goo.gl/5adZ7

Aunque el orden sea distinto, siguen considerándose en este caso como las más populares, según el uso que hacen de ellas los usuarios en la actualidad con las nuevas Tecnologías de la Información y las Comunicaciones (TIC), las aplicaciones Facebook, Twitter, Tuenti y Flickr. La importancia de las citadas herramientas en los menores de edad es tal, que la Fundación Save the Children, en colaboración con el Ministerio de Sanidad, Servicios Sociales e Igualdad y la Obra Social Caja Madrid, han promovido una página web en la que explican con detalle los riesgos derivados del uso de las redes sociales, entre las que se incluyen aquellas que forman parte de nuestro objeto de estudio (figura 2).

Otro ejemplo de la importancia de estas redes sociales se encuentra en el uso que de ellas hacen algunas instituciones públicas relevantes, como la Diputación de Valencia de la que el diario digital El Mercantil Valenciano (2010) publicó: "La Diputación de Valencia se ha sumergido de lleno en las nuevas tecnologías al estrenar un blog institucional ("El blog de la dipu"), un canal propio en Youtube y perfil en las cinco principales redes sociales (Facebook, Tuenti, Twitter, Flickr, Wordpress), dentro del proyecto "La dipu en la red", que ayer fue presentado a los medios de comunicación. [...]" o el caso del Ayuntamiento de Algeciras que en marzo de 2012, lanzó "una campaña de redes sociales en las que abarca cuatro de las más importantes del momento: Facebook, Twitter, Tuenti y Flickr". 


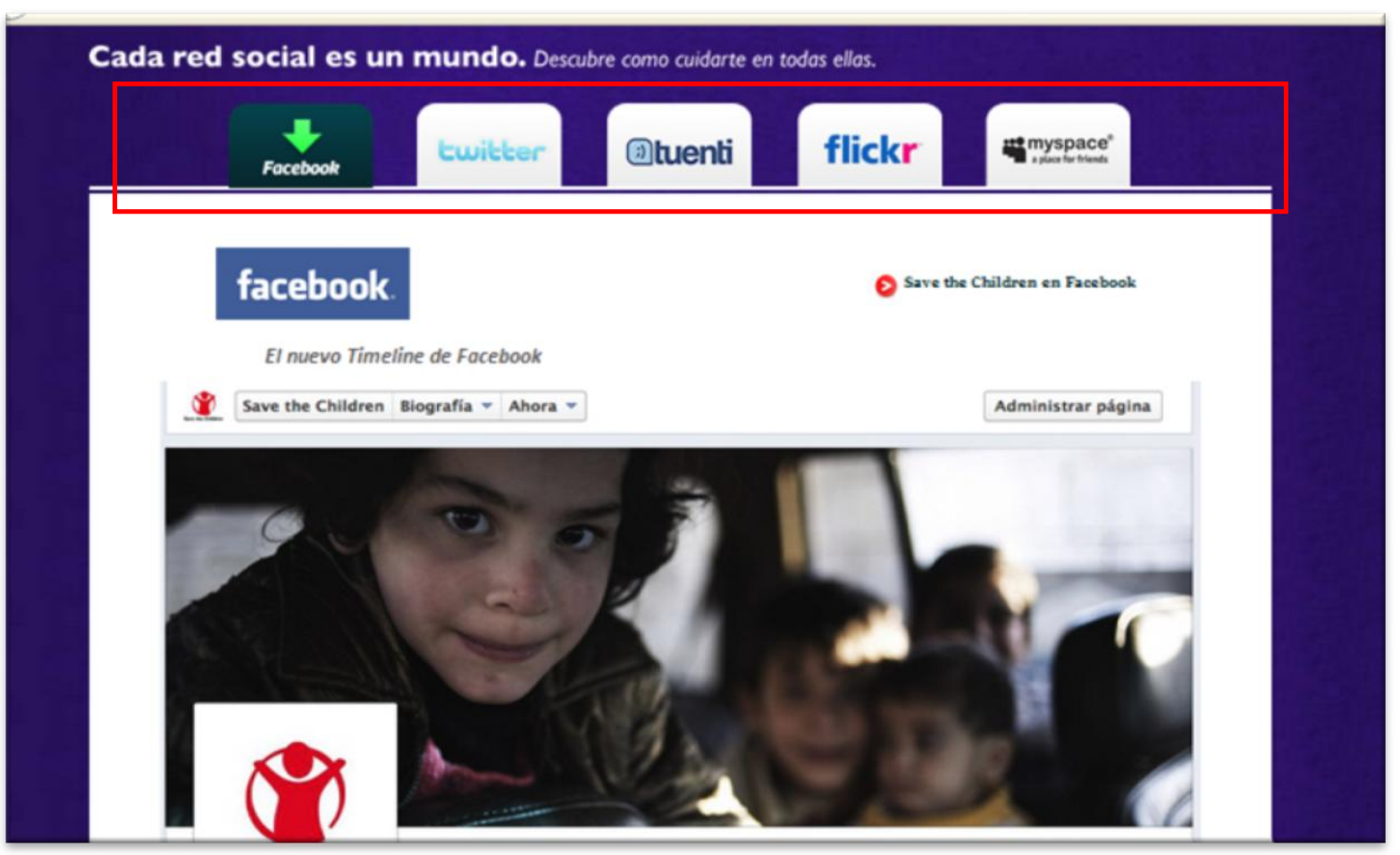

Figura 2 - Consejos sobre la utilización de las redes sociales que forman parte del objeto de estudio. Fuente: Fundación Save the Children (2011). ¡De aquí no pasas! Recuperado de http://www.deaquinopasas.org/

Finalmente, según una publicación en la red social de los inversores, directivos y empresarios elEconomista.es (2010), bajo el título de “¿Cuál es la mejor red social? Vote por su favorita”, las seis mejores redes sociales son las siguientes (tabla 2):

\begin{tabular}{|c|c|c|}
\hline Ubicación & Red social & Puntos obtenidos \\
\hline 1 & Facebook & 8.500 \\
\hline 2 & Tuenti & 6.200 \\
\hline 3 & Twitter & 4.850 \\
\hline 4 & Myspace & 2.350 \\
\hline 5 & Flickr & 1.910 \\
\hline 6 & Linked in & 1.830 \\
\hline
\end{tabular}

Tabla 3 - Ranking de redes sociales más utilizadas realizado por el elEconomista.es. Fuente: Tati (2010). ¿Cuál es la mejor red social? Vote por su favorita. elEconomista.es: la red social de los inversores, directivos y empresarios. Recuperado de http://goo.gl/K6yaQ

Si descartaramos Myspace, por ser una red de entretenimiento social, que no se ajusta a los objetivos planteados de este proyecto, se puede comprobar que las cuatro redes sociales restantes son, al igual que en los anteriores ejemplos mostrados, las herramientas más utilizadas y visitadas en la actualidad, y que por tanto serán las que se examinarán con detenimiento en los siguientes apartados.

Las características de estas aplicaciones 2.0 según la página web Dosdoce (2012) son (tabla 3$)^{13}$ : 


\begin{tabular}{|c|c|c|c|c|c|c|c|c|c|c|}
\hline & & & & & \multirow{2}{*}{\multicolumn{2}{|c|}{ A determinar }} & \multirow{2}{*}{\multicolumn{2}{|c|}{ No recomendado }} & & \\
\hline & & \multicolumn{2}{|r|}{ USO: } & Excelente & & & & & & \\
\hline & & $\begin{array}{l}\text { Gestión de } \\
\text { reputación } \\
\text { digital }\end{array}$ & $\begin{array}{c}\text { Comunicación } \\
\text { corporativa }\end{array}$ & $\begin{array}{l}\text { Comunicación de } \\
\text { productos/eventos }\end{array}$ & Visibilidad & $\begin{array}{l}\text { Prevención de } \\
\text { crisis }\end{array}$ & $\begin{array}{l}\text { Atención al } \\
\text { cliente }\end{array}$ & $\begin{array}{c}\text { Gestión de } \\
\text { conocimiento }\end{array}$ & Comunicación interna & $\begin{array}{l}\text { Captación de } \\
\text { talento }\end{array}$ \\
\hline 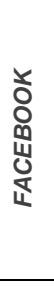 & $\begin{array}{l}\text { Red social generalista } \\
\text { más popular en todo el } \\
\text { mundo. Los usuarios } \\
\text { publican y comparten } \\
\text { todo tipo de } \\
\text { información, personal y } \\
\text { profesional. }\end{array}$ & $\begin{array}{l}\text { Muy potente. } \\
\text { Permite captar } \\
\text { gente, que } \\
\text { muestra en su } \\
\text { perfil que la } \\
\text { marca "le gusta". } \\
\text { Cuenta mayor } \\
\text { interacción } \\
\text { haya, más } \\
\text { visibilidad. }\end{array}$ & $\begin{array}{l}\text { Muy potente. El } \\
\text { "problema" es la } \\
\text { saturación. Cada } \\
\text { vez hay más } \\
\text { empresas, } \\
\text { páginas, perfiles... } \\
\text { y es difícil } \\
\text { destacar. }\end{array}$ & $\begin{array}{l}\text { Excelente. Actividades } \\
\text { presenciales o } \\
\text { virtuales que pueden } \\
\text { ver todos los usuarios } \\
\text { de la red sin tener que } \\
\text { ser contactos). }\end{array}$ & $\begin{array}{l}\text { Buena } \\
\text { herramienta, } \\
\text { aunque los } \\
\text { motores de } \\
\text { búsqueda aún } \\
\text { no la registren } \\
\text { bien. }\end{array}$ & $\begin{array}{l}\text { Puede permitir } \\
\text { detectar } \\
\text { rumores o } \\
\text { quejas de } \\
\text { forma } \\
\text { temprana. }\end{array}$ & $\begin{array}{l}\text { Excelente } \\
\text { herramienta de } \\
\text { contacto con el } \\
\text { usuario. }\end{array}$ & $\begin{array}{l}\text { Buen canal para } \\
\text { compartir } \\
\text { información e } \\
\text { intercambiar } \\
\text { opiniones. }\end{array}$ & $\begin{array}{l}\text { Su potencial depende } \\
\text { de la implicación que se } \\
\text { logre con los } \\
\text { empleados. Buena } \\
\text { opción para eventos, } \\
\text { actividades y } \\
\text { novedades de la } \\
\text { organización. }\end{array}$ & $\begin{array}{l}\text { Publicar } \\
\text { búsquedas, recibir } \\
\text { respuestas } \\
\text { inmediatas y } \\
\text { encontrar perfiles } \\
\text { interesantes } \\
\text { aunque no estén en } \\
\text { el mercado. }\end{array}$ \\
\hline 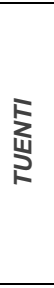 & $\begin{array}{l}\text { Red social generalista, } \\
\text { fundamentalmente } \\
\text { dirigida a gente joven. } \\
\text { Los usuarios publican y } \\
\text { comparten todos tipo } \\
\text { de información, } \\
\text { personal y profesional }\end{array}$ & $\begin{array}{l}\text { Muy potente. La } \\
\text { edad media de } \\
\text { los usuarios } \\
\text { reduce el } \\
\text { espectro, pero } \\
\text { permite } \\
\text { segmentar muy } \\
\text { bien. Son los } \\
\text { usuarios más } \\
\text { participativos. } \\
\end{array}$ & $\begin{array}{l}\text { Muy potente. Es } \\
\text { reciente la opción } \\
\text { de páginas de } \\
\text { empresa: más } \\
\text { fácil llegar con un } \\
\text { buen perfil. Menor } \\
\text { competencia: es } \\
\text { posible destacar. }\end{array}$ & $\begin{array}{l}\text { Excelente. Con } \\
\text { muchas opciones } \\
\text { imaginativas y } \\
\text { pensadas para el } \\
\text { público específico de } \\
\text { la red (vídeos, etc.). }\end{array}$ & $\begin{array}{l}\text { Buena } \\
\text { herramienta, } \\
\text { aunque los } \\
\text { motores de } \\
\text { búsqueda aún } \\
\text { no la registren } \\
\text { bien }\end{array}$ & $\begin{array}{l}\text { Puede permitir } \\
\text { detectar } \\
\text { rumores o } \\
\text { quejas de } \\
\text { forma } \\
\text { temprana }\end{array}$ & $\begin{array}{l}\text { Excelente } \\
\text { herramienta de } \\
\text { contacto con el } \\
\text { cliente }\end{array}$ & $\begin{array}{l}\text { Buena. } \\
\text { Respuestas } \\
\text { inmediatas del } \\
\text { público objetivo } \\
\text { (muy bien } \\
\text { segmentando) } \\
\text { pero el alcance } \\
\text { puede ser limitado } \\
\text { si se pretende } \\
\text { llegar a expertos } \\
\end{array}$ & $\begin{array}{l}\text { Su potencial dependen } \\
\text { de las características de } \\
\text { la red (edad media de } \\
\text { los usuarios) y varía } \\
\text { mucho según la } \\
\text { compañía }\end{array}$ & $\begin{array}{l}\text { Más indicando para } \\
\text { algunos sectores: } \\
\text { educación, ONGs, } \\
\text { voluntariado y } \\
\text { menos para perfiles } \\
\text { corporativos y muy } \\
\text { técnicos }\end{array}$ \\
\hline$\stackrel{\frac{\alpha}{w}}{5}$ & $\begin{array}{l}\text { Herramienta de } \\
\text { microblogging, que } \\
\text { permite enviar } \\
\text { mensajes con un } \\
\text { máximo de } 140 \\
\text { caracteres de forma } \\
\text { instantánea y gratuita a } \\
\text { sus seguidores. Canal } \\
\text { bidireccional muy } \\
\text { potente. Permite } \\
\text { adjuntar vídeos, fotos, } \\
\text { archivos, etc. }\end{array}$ & $\begin{array}{l}\text { Potente para } \\
\text { gestión de } \\
\text { reputación. Para } \\
\text { ser efectivo: } \\
\text { conversar, } \\
\text { interactuar, ser } \\
\text { transparente y } \\
\text { aportar } \\
\text { contenido } \\
\text { interesante y } \\
\text { creativo. }\end{array}$ & $\begin{array}{l}\text { Canal muy } \\
\text { potente. Hay que } \\
\text { conocer el canal, } \\
\text { tener una } \\
\text { estrategia clara, } \\
\text { interactuar de } \\
\text { forma constante y } \\
\text { verticalizar la } \\
\text { comunicación. }\end{array}$ & $\begin{array}{l}\text { Potente para } \\
\text { comunicar el } \\
\text { lanzamiento de } \\
\text { productos/servicios. } \\
\text { Retroalimentación } \\
\text { constante. Excelente } \\
\text { para investigación de } \\
\text { mercado. }\end{array}$ & $\begin{array}{l}\text { Excelente } \\
\text { herramienta } \\
\text { para aumentar } \\
\text { la visibilidad de } \\
\text { la empresa y } \\
\text { generar tráfico } \\
\text { a nuestra web } \\
\text { o a nuestros } \\
\text { blogs. }\end{array}$ & $\begin{array}{l}\text { Permite } \\
\text { detectar } \\
\text { rumores o } \\
\text { quejas de } \\
\text { forma } \\
\text { temprana. Su } \\
\text { eficacia en la } \\
\text { prevención de } \\
\text { crisis } \\
\text { dependerá de } \\
\text { la correcta } \\
\text { gestión del } \\
\text { canal. } \\
\end{array}$ & $\begin{array}{l}\text { Excelente } \\
\text { herramienta: } \\
\text { com. directa y } \\
\text { rápida, } \\
\text { resolución en } \\
\text { tiempo real. } \\
\text { Implica } \\
\text { accesibilidad, si } \\
\text { se interactúa y } \\
\text { no se hace } \\
\text { SPAM. }\end{array}$ & $\begin{array}{l}\text { Excelente canal } \\
\text { para compartir } \\
\text { conocimiento. Útil } \\
\text { para plantear } \\
\text { dudas y } \\
\text { ofrecer/lograr } \\
\text { respuestas. } \\
\text { Posibilidad de } \\
\text { enlazar y compartir } \\
\text { presentaciones. }\end{array}$ & $\begin{array}{l}\text { Se pueden sustituir } \\
\text { mails, Ilamadas o } \\
\text { incluso reuniones } \\
\text { interdepartamentales } \\
\text { por tweets. Implica } \\
\text { transparencia y } \\
\text { accesibilidad de } \\
\text { directivos. }\end{array}$ & $\begin{array}{l}\text { Permite conocer a } \\
\text { las personas más } \\
\text { relevantes, publicar } \\
\text { ofertas y recibir } \\
\text { respuestas } \\
\text { inmediatamente. } \\
\text { Potente } \\
\text { intercambio y } \\
\text { viralidad de ofertas. }\end{array}$ \\
\hline$\frac{\substack{\frac{1}{4} \\
\frac{x}{4}}}{4}$ & $\begin{array}{l}\text { Publicación de fotos } \\
\text { que pueden ser vistas, } \\
\text { compartidas y } \\
\text { descargadas por los } \\
\text { usuarios de la Red. }\end{array}$ & $\begin{array}{l}\text { Buena para } \\
\text { crear o reforzar } \\
\text { marca y su } \\
\text { imagen, con } \\
\text { valor añadido y } \\
\text { buenas } \\
\text { descripciones y } \\
\text { etiquetas. }\end{array}$ & $\begin{array}{l}\text { Buena } \\
\text { herramienta para } \\
\text { trasladar } \\
\text { imágenes de } \\
\text { interés para la } \\
\text { compañía. } \\
\text { Perfecta para } \\
\text { mostrar la imagen } \\
\text { corporativa. }\end{array}$ & $\begin{array}{l}\text { Refuerza la } \\
\text { comunicación, } \\
\text { especialmente con los } \\
\text { medios, con imágenes } \\
\text { variadas y de calidad. }\end{array}$ & $\begin{array}{l}\text { Excelente } \\
\text { herramienta, } \\
\text { bien registrada } \\
\text { en los motores } \\
\text { de búsqueda y } \\
\text { exportable a } \\
\text { otros canales. }\end{array}$ & $\begin{array}{l}\text { Débil. } \\
\text { Únicamente } \\
\text { cuando haya } \\
\text { que reforzar el } \\
\text { mensaje con } \\
\text { imágenes } \\
\text { volcadas en } \\
\text { otros canales. }\end{array}$ & $\begin{array}{l}\text { Herramienta } \\
\text { débil para la } \\
\text { atención al } \\
\text { cliente. }\end{array}$ & $\begin{array}{l}\text { La validez del } \\
\text { canal para } \\
\text { compartir sabiduría } \\
\text { es muy relativa. }\end{array}$ & $\begin{array}{l}\text { Validez limitada, poco } \\
\text { más allá de dar a } \\
\text { conocer nombramientos } \\
\text { o eventos. }\end{array}$ & $\begin{array}{l}\text { No válida para la } \\
\text { captación de } \\
\text { talento. }\end{array}$ \\
\hline
\end{tabular}

Tabla 4 - Características de las redes sociales analizadas. Fuente: Dosdoce. (2012). Chuleta de las redes sociales en España. Recuperado de http://goo.gl/9DQ1r. 
El siguiente paso dado en el proceso metodológico fue el de ir observando cuáles de las instituciones académicas escogidas disponen todas o algunas de las cuatro redes sociales.

Finalmente se realizó un análisis comparativo de los centros de enseñanza que sí disponían de alguna red social. Para realizarlo se estudió: el número de usuarios registrados ${ }^{14}$, el de noticias publicadas ${ }^{15}$ y la cantidad de comentarios, marcas y/o retweets ${ }^{16}$ en cada uno de los perfiles sociales. Estos datos fueron consultados en enero de 2012.

\section{Resultados}

El análisis de cuáles de las instituciones académicas escogidas poseen todas o algunas de las cuatro redes sociales da como resultado la siguiente tabla (tabla 4).

\begin{tabular}{|c|c|c|c|c|}
\hline \multirow{2}{*}{ Universidad / Facultad } & \multicolumn{4}{|c|}{ Red Social (R.S.) } \\
\hline & Facebook & Tuenti & Twitter & Flickr \\
\hline U. Abierta de Cataluña / F. de Ciencias de la Información y de la Comunicación & $x$ & $x$ & $x$ & $x$ \\
\hline U. Autónoma de Barcelona / F. de Ciencias de la Comunicación & $x$ & $x$ & $\checkmark$ & $x$ \\
\hline U. Carlos III / F. de Humanidades, Comunicación y Documentación & $\checkmark$ & $x$ & $\checkmark$ & $x$ \\
\hline U. Complutense de Madrid / F. de Ciencias de la Documentación & $\checkmark$ & $\checkmark$ & $x$ & $x$ \\
\hline U. de Alcalá / F. de Documentación & $\checkmark$ & $\checkmark$ & $x$ & $x$ \\
\hline U. de Barcelona / F. de Biblioteconomía y Documentación & $\checkmark$ & $x$ & $x$ & $x$ \\
\hline U. de Extremadura / F. de Biblioteconomía y Documentación & $x$ & $x$ & $x$ & $x$ \\
\hline U. de Granada / F. de Comunicación y Documentación & $\checkmark$ & $x$ & $\checkmark$ & $x$ \\
\hline U. de La Coruña / F. de Humanidades & $\checkmark$ & $x$ & $x$ & $x$ \\
\hline U. de León / F. de Filosofía y Letras & $\checkmark$ & $\checkmark$ & $x$ & $x$ \\
\hline U. de Murcia / F. de Comunicación y Documentación & $\checkmark$ & $\checkmark$ & $x$ & $x$ \\
\hline U. de Salamanca / F. de Traducción y Documentación & $\checkmark$ & $\checkmark$ & $x$ & $x$ \\
\hline U. de Valencia / F. de Geografía e Historia & $x$ & $\checkmark$ & $x$ & $x$ \\
\hline U. de Vic / F. de Educación, Traducción y Ciencias Humanas & $\checkmark$ & $x$ & $x$ & $x$ \\
\hline U. de Zaragoza / F. de Filosofía y Letras & $\checkmark$ & $\checkmark$ & $x$ & $x$ \\
\hline U. Politécnica de Valencia / Escuela Técnica Superior de Ingeniería Informática & $\checkmark$ & $x$ & $\checkmark$ & $x$ \\
\hline
\end{tabular}

Tabla 5 - Universidades/Facultades y redes sociales de las que disponen. Fuente: Elaboración propia.

Tal y como se puede observar en la figura anterior, la red social Facebook aparece en 12 de las 16 universidades (75\% de la muestra); Tuenti aparece en 7 de las 16 universidades (43,75\% de la muestra); Twitter aparece en 4 de las 16 universidades (25\% de la muestra); Flickr no aparece, ya que ninguna facultad posee esta aplicación 2.0.

Por su parte, por medio del análisis comparativo de los centros de enseñanza que sí disponen alguna de las redes sociales, se obtiene la siguiente tabla (tabla 5): 


\begin{tabular}{|c|c|c|c|c|}
\hline Universidad / Facultad & R.S. & $\begin{array}{l}\mathrm{N}^{\circ} \\
\text { usuarios }\end{array}$ & $\begin{array}{l}\mathrm{N}^{\circ} \text { publicaciones } \\
\text { (incluye tweets) }\end{array}$ & $\mathrm{N}^{\circ}$ comentarios \\
\hline \multirow{4}{*}{$\begin{array}{l}\text { U. Abierta de Cataluña / F. de Ciencias de la Información y de } \\
\text { la Comunicación }\end{array}$} & Facebook & - & - & - \\
\hline & Tuenti & - & - & - \\
\hline & Twitter & - & - & - \\
\hline & Flickr & - & - & - \\
\hline \multirow{4}{*}{$\begin{array}{l}\text { U. Autónoma de Barcelona / F. de Ciencias de la } \\
\text { Comunicación }\end{array}$} & Facebook & - & - & - \\
\hline & Tuenti & - & - & - \\
\hline & Twitter & 560 & 358 & - \\
\hline & Flickr & - & - & - \\
\hline \multirow{4}{*}{$\begin{array}{l}\text { U. Carlos III / F. de Humanidades, Comunicación y } \\
\text { Documentación }\end{array}$} & Facebook & 459 & 173 & 37 \\
\hline & Tuenti & - & - & - \\
\hline & Twitter & 286 & 185 & - \\
\hline & Flickr & - & - & - \\
\hline \multirow{4}{*}{$\begin{array}{l}\text { U. Complutense de Madrid / F. de Ciencias de la } \\
\text { Documentación }\end{array}$} & Facebook & 245 & 138 & 41 \\
\hline & Tuenti & 8 & 0 & 0 \\
\hline & Twitter & - & - & - \\
\hline & Flickr & - & - & - \\
\hline \multirow{4}{*}{ U. de Alcalá / F. de Documentación } & Facebook & 205 & 214 & 32 \\
\hline & Tuenti & 1 & 14 & 0 \\
\hline & Twitter & - & - & - \\
\hline & Flickr & - & - & - \\
\hline \multirow{4}{*}{ U. de Barcelona / F. de Biblioteconomía y Documentación } & Facebook & 256 & 148 & 46 \\
\hline & Tuenti & - & - & - \\
\hline & Twitter & - & - & - \\
\hline & Flickr & - & - & - \\
\hline \multirow{4}{*}{ U. de Extremadura / F. de Biblioteconomía y Documentación } & Facebook & - & - & - \\
\hline & Tuenti & - & - & - \\
\hline & Twitter & - & - & - \\
\hline & Flickr & - & - & - \\
\hline
\end{tabular}

Tabla 6 (Continua)- Comparación de los centros de enseñanza que sí disponen de alguna de las redes sociales. Fuente: Elaboración propia. 


\begin{tabular}{|c|c|c|c|c|}
\hline Universidad / Facultad & R.S. & $\begin{array}{c}\mathrm{N}^{\circ} \\
\text { usuarios }\end{array}$ & $\begin{array}{c}\mathrm{N}^{\circ} \text { publicaciones } \\
\text { (incluye tweets) }\end{array}$ & $\begin{array}{c}\mathrm{N}^{\circ} \\
\text { comentarios }\end{array}$ \\
\hline \multirow{4}{*}{ U. de Granada / F. de Comunicación y Documentación } & Facebook & 165 & 27 & 1 \\
\hline & Tuenti & - & - & - \\
\hline & Twitter & 58 & 19 & - \\
\hline & Flickr & - & - & - \\
\hline \multirow{4}{*}{ U. de La Coruña / F. de Humanidades } & Facebook & 2 & 0 & 0 \\
\hline & Tuenti & - & - & - \\
\hline & Twitter & - & - & - \\
\hline & Flickr & - & - & - \\
\hline \multirow{4}{*}{ U. de León / F. de Filosofía y Letras } & Facebook & 50 & 22 & 3 \\
\hline & Tuenti & 1 & 0 & 0 \\
\hline & Twitter & - & - & - \\
\hline & Flickr & - & - & - \\
\hline \multirow{4}{*}{ U. de Murcia / F. de Comunicación y Documentación } & Facebook & 3 & 0 & 0 \\
\hline & Tuenti & 302 & 1 & 43 \\
\hline & Twitter & - & - & - \\
\hline & Flickr & - & - & - \\
\hline \multirow{4}{*}{ U. de Salamanca / F. de Traducción y Documentación } & Facebook & 858 & 144 & 68 \\
\hline & Tuenti & \multicolumn{3}{|c|}{ Es necesario solicitar una petición de amistad } \\
\hline & Twitter & - & - & - \\
\hline & Flickr & - & - & - \\
\hline \multirow{4}{*}{ U. de Valencia / F. de Geografía e Historia } & Facebook & - & - & - \\
\hline & Tuenti & 18 & 0 & 1 \\
\hline & Twitter & - & - & - \\
\hline & Flickr & - & - & - \\
\hline \multirow{4}{*}{ U. de Vic / F. de Educación, Traducción y Ciencias Humanas } & Facebook & 6 & 0 & 0 \\
\hline & Tuenti & - & - & - \\
\hline & Twitter & - & - & - \\
\hline & Flickr & - & - & - \\
\hline
\end{tabular}

Tabla 7 (Continua) - Comparación de los centros de enseñanza que sí disponen de alguna de las redes sociales. Fuente: Elaboración propia. 


\begin{tabular}{|c|c|c|c|c|}
\hline Universidad / Facultad & R.S. & $\begin{array}{l}\mathrm{N}^{\circ} \\
\text { usuarios }\end{array}$ & $\begin{array}{l}\mathrm{N}^{\circ} \text { publicaciones } \\
\text { (incluye tweets) }\end{array}$ & $\begin{array}{l}\mathrm{N}^{\circ} \\
\text { comentarios }\end{array}$ \\
\hline \multirow{4}{*}{ U. de Zaragoza / F. de Filosofía y Letras } & Facebook & 13 & 0 & 0 \\
\hline & Tuenti & 32 & 0 & 1 \\
\hline & Twitter & - & - & - \\
\hline & Flickr & - & - & - \\
\hline \multirow{4}{*}{$\begin{array}{l}\text { U. Politécnica de Valencia / Escuela Técnica Superior de } \\
\text { Ingeniería Informática }\end{array}$} & Facebook & 1.121 & 432 & 30 \\
\hline & Tuenti & - & - & - \\
\hline & Twitter & 478 & 590 & - \\
\hline & Flickr & - & - & - \\
\hline
\end{tabular}

Tabla 8 (Conclusión) - Comparación de los centros de enseñanza que sí disponen de alguna de las redes sociales. Fuente: Elaboración propia.

Teniendo en cuenta los datos de la tabla anterior se puede decir que en referencia a la herramienta Facebook, la Escuela Técnica Superior de Ingeniería Informática de la Universidad Politécnica de Valencia es la que más usuarios tiene registrados en esta aplicación con 1.121 usuarios, seguida de la Facultad de Traducción y Documentación de la Universidad de Salamanca con 858 usuarios y la Facultad de Humanidades, Comunicación y Documentación de la Universidad Carlos III con 459. Sin embargo, la Facultad de Educación, Traducción y Ciencias Humanas de la Universidad de Vich, la Facultad de Comunicación y Documentación de la Universidad de Murcia y la Facultad de Humanidades de la Universidad de la Coruña son las que menos usuarios registrados poseen en esta red social, con 6,3 y 2 usuarios respectivamente. No obstante, cabe destacar que la Facultad de Comunicación y Documentación de la Universidad de Murcia tiene una revista digital en esta red social "revista digital C'mon", la cual tiene 85 usuarios (figura 3).

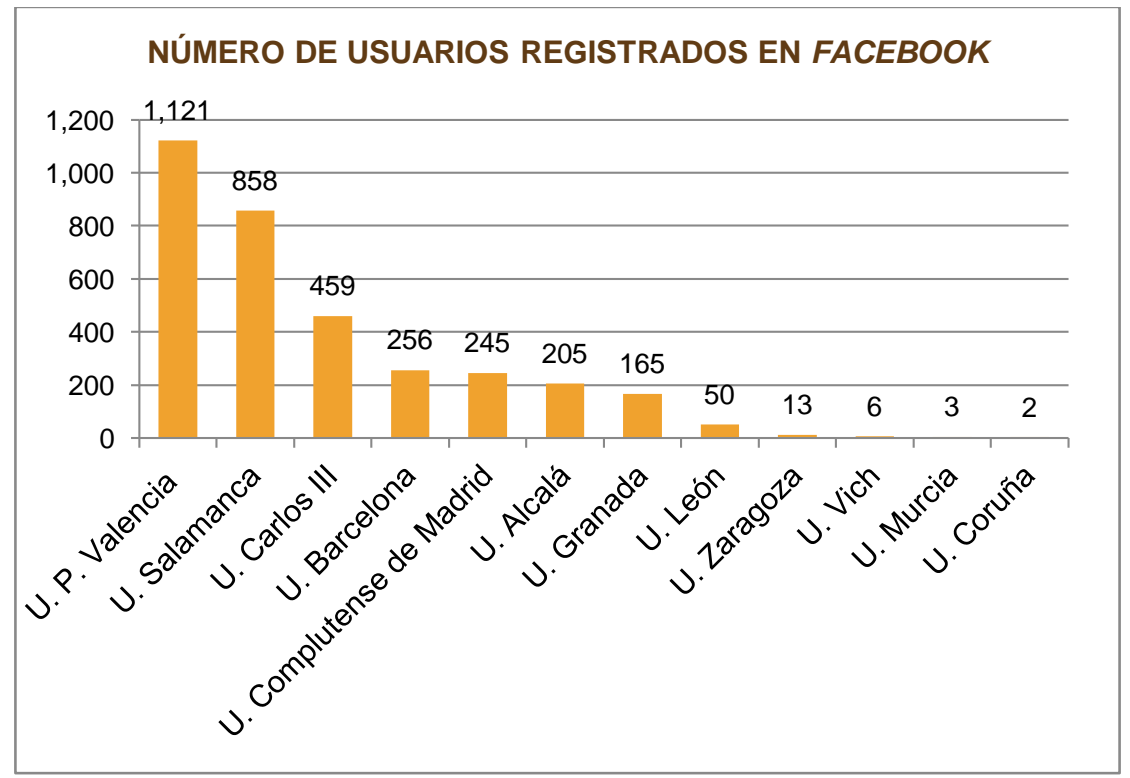

Figura 3 - Número de usuarios registrados en Facebook por cada una de las facultades que imparten titulaciones del ámbito de Información y Documentación. Fuente: Elaboración propia ${ }^{17}$.

En cuanto al número de publicaciones, nuevamente la página de la Escuela Técnica Superior de Ingeniería Informática de la Universidad Politécnica de Valencia vuelve a estar en primera posición con 432 publicaciones, 
seguida de la Facultad de Documentación de la Universidad de Alcalá con 214 publicaciones. Sin embargo, la Facultad de Comunicación y Documentación de la Universidad de Murcia, la Facultad de Humanidades de la Universidad de la Coruña, la Facultad de Educación, Traducción y Ciencias Humanas de la Universidad de Vich y la Facultad de Filosofía y Letras de la Universidad de Zaragoza no han realizado ninguna publicación (figura 4).

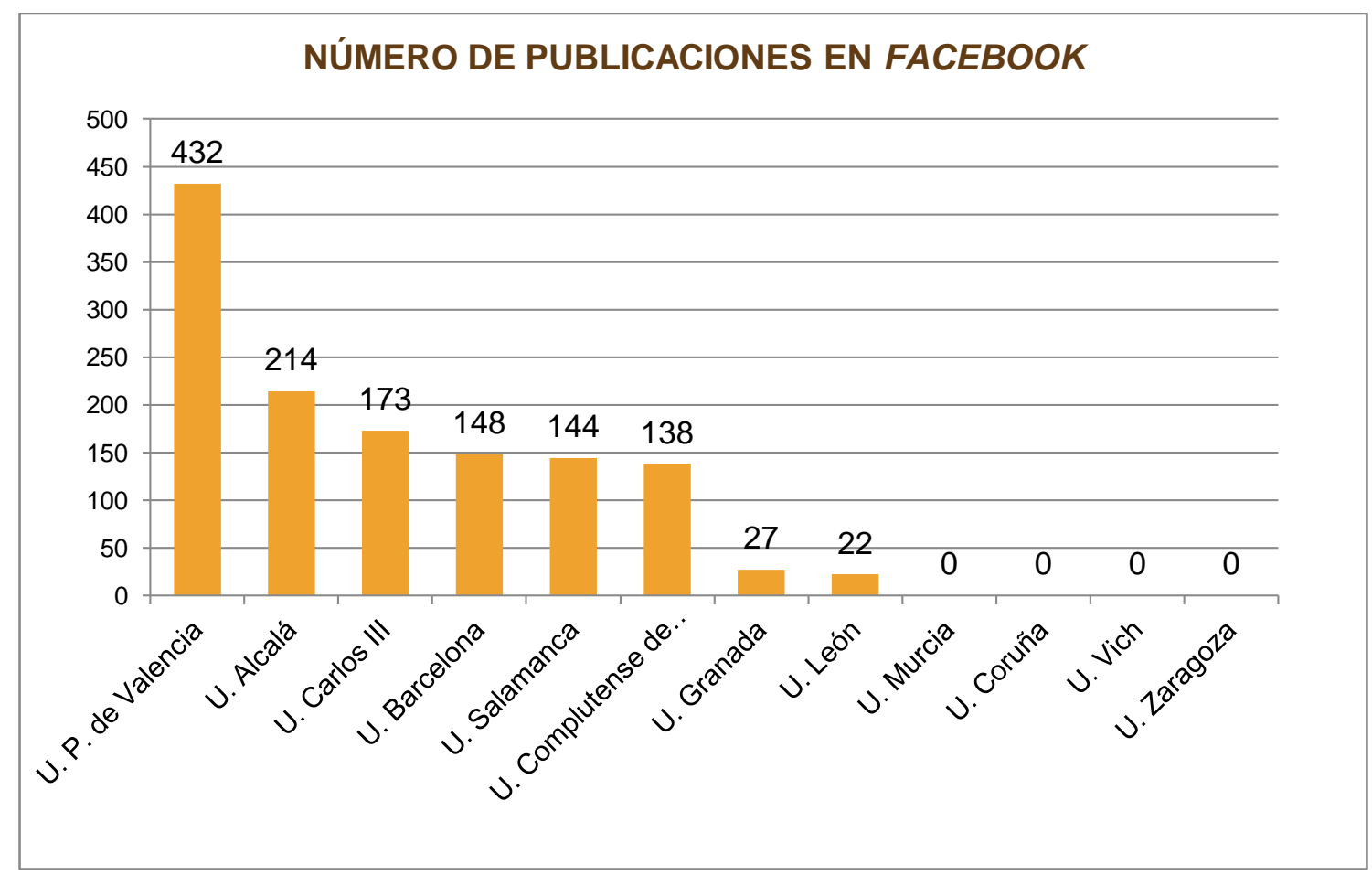

Figura 4 - Número de publicaciones en Facebook por cada una de las facultades que imparten titulaciones del ámbito de Información y Documentación. Fuente: Elaboración propia.

En cuanto al número de comentarios, la Facultad de Traducción y Documentación de la Universidad de Salamanca se pone en primera posición con 68 comentarios, seguida de la Facultad de Biblioteconomía y Documentación de la Universidad de Barcelona con 46. Nuevamente, la Facultad de Comunicación y Documentación de la Universidad de Murcia, la Facultad de Humanidades de la Universidad de la Coruña, la Facultad de Educación, Traducción y Ciencias Humanas de la Universidad de Vich y la Facultad de Filosofía y Letras de la Universidad de Zaragoza no han realizado ningún comentario (figura 5). 


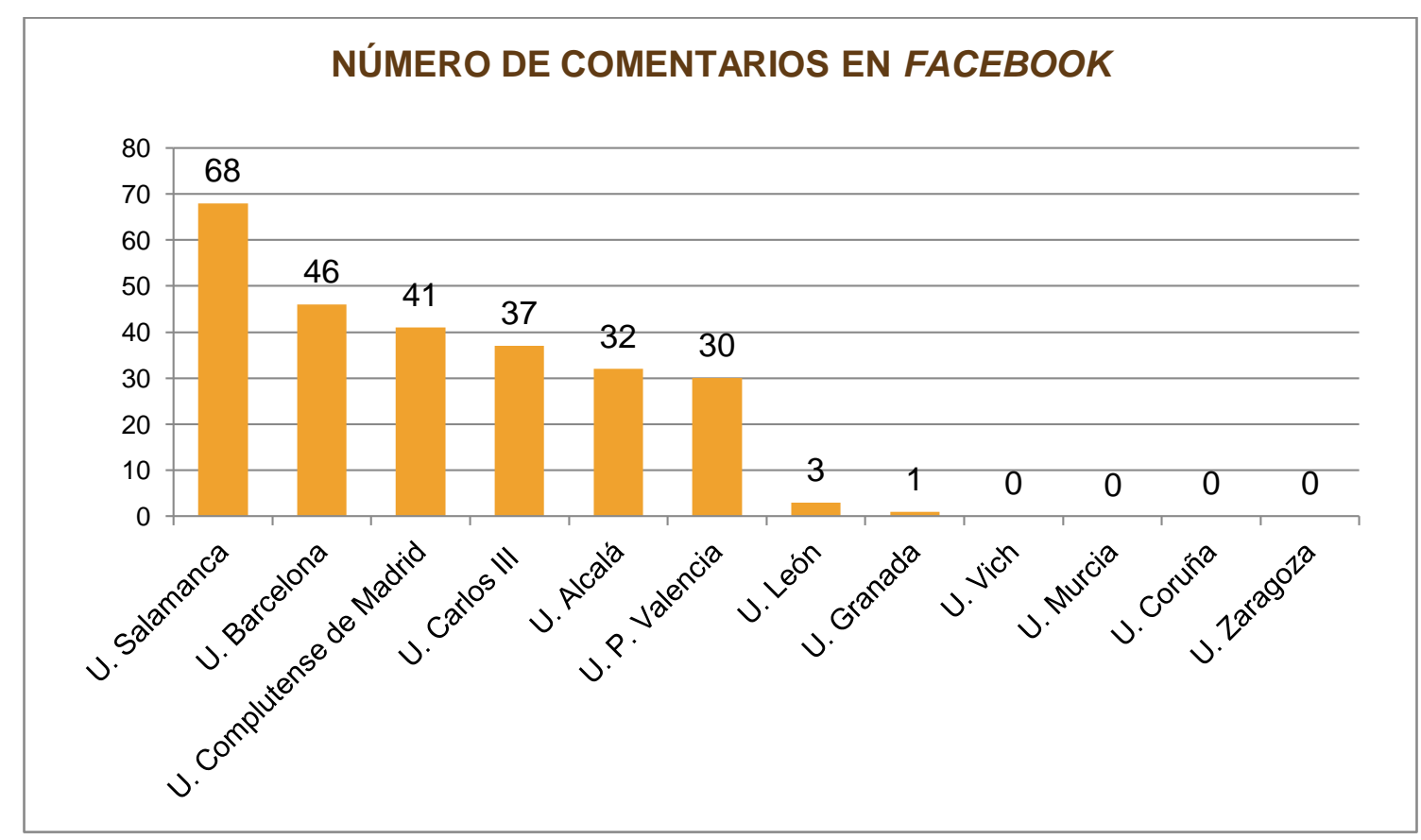

Figura 5 - Número de comentarios en Facebook por cada una de las facultades que imparten titulaciones del ámbito de Información y Documentación. Fuente: Elaboración propia.

La siguiente red social que tendríamos que discutir es $\underline{\text { Flickr }}$, pero dado que ninguna de las facultades de las dieciséis universidades de la muestra tiene una página oficial en esta red social, pasamos a exponer los resultados relativos a la herramienta $\underline{\text { Tuenti. }}$.

Según los datos obtenidos, el número de usuarios registrados en la página de la Facultad de Comunicación y Documentación de la Universidad de Murcia es muy alto (302) en comparación con las otras universidades de la muestra, llegando a decuplicar a la siguiente que le sigue, y, por tanto, situándose a la cabeza de todas. Por otro lado, la Facultad de Filosofía y Letras de la Universidad de León y la Facultad de Documentación de la Universidad de Alcalá sólo tienen registrado a un usuario y la Facultad de Traducción y Documentación de la Universidad de Salamanca tiene un perfil privado al que sólo se puede acceder con una petición de amistad (figura 6). 


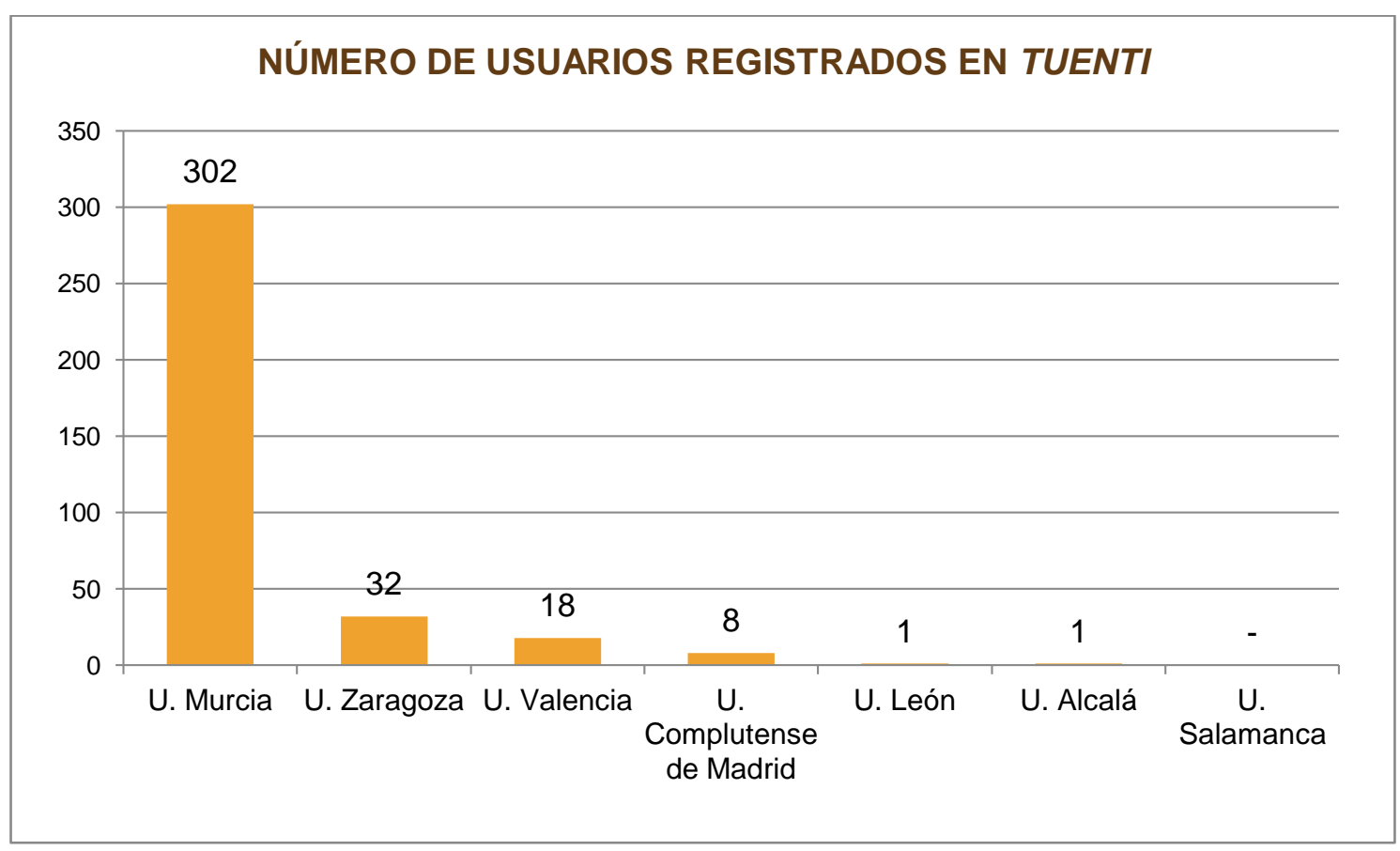

Figura 6 - Número de usuarios registrados en Tuenti por cada una de las facultades que imparten titulaciones del ámbito de Información y Documentación. Fuente: Elaboración propia.

En cuanto al número de publicaciones, la Facultad de Documentación de la Universidad de Alcalá se queda en primera posición con 14 publicaciones, seguida de la Facultad de Comunicación y Documentación de la Universidad de Murcia, con una publicación. Sin embargo, el resto de facultades o escuelas no tienen ninguna publicación (figura 7).

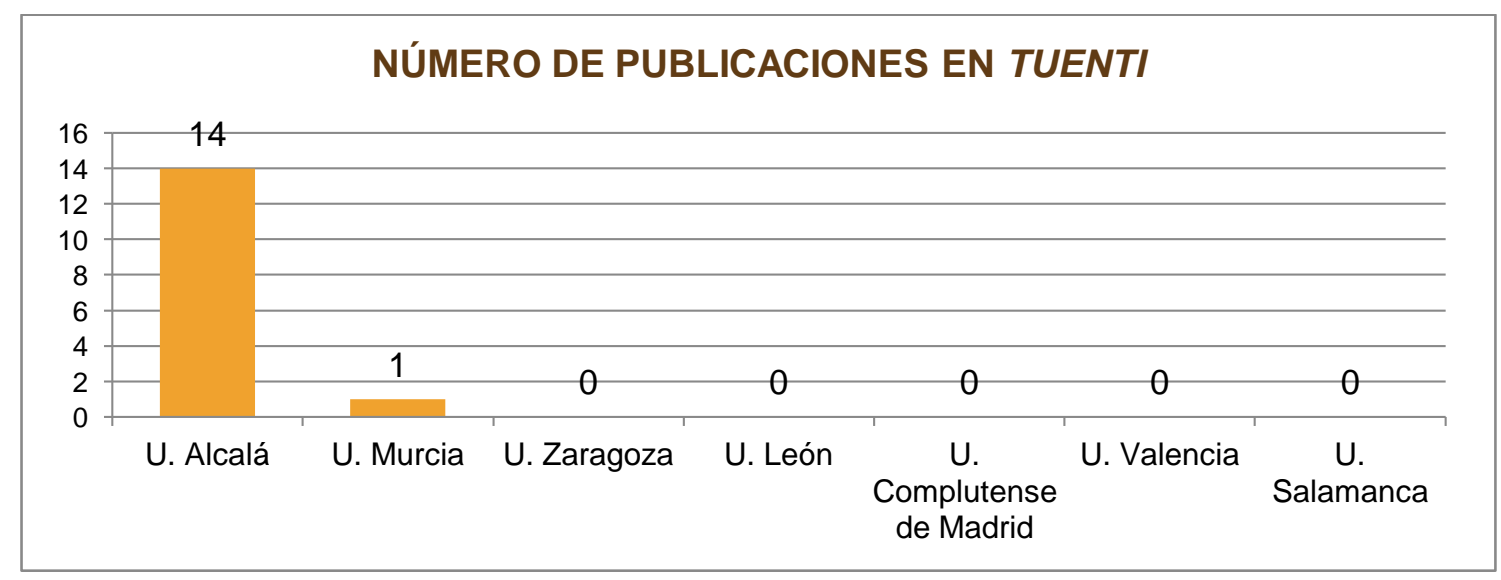

Figura 7 - Número de publicaciones en Tuenti por cada una de las facultades que imparten titulaciones del ámbito de Información y Documentación. Fuente: Elaboración propia.

Finalmente, en referencia al número de comentarios, la página de la Facultad de Comunicación y Documentación de la Universidad de Murcia destaca con 43 comentarios, situándose en primera posición, seguida de un comentario de la Facultad de Filosofía y Letras de la Universidad de Zaragoza y otro de la Facultad de Geografía e Historia de la Universidad de Valencia (figura 8). 


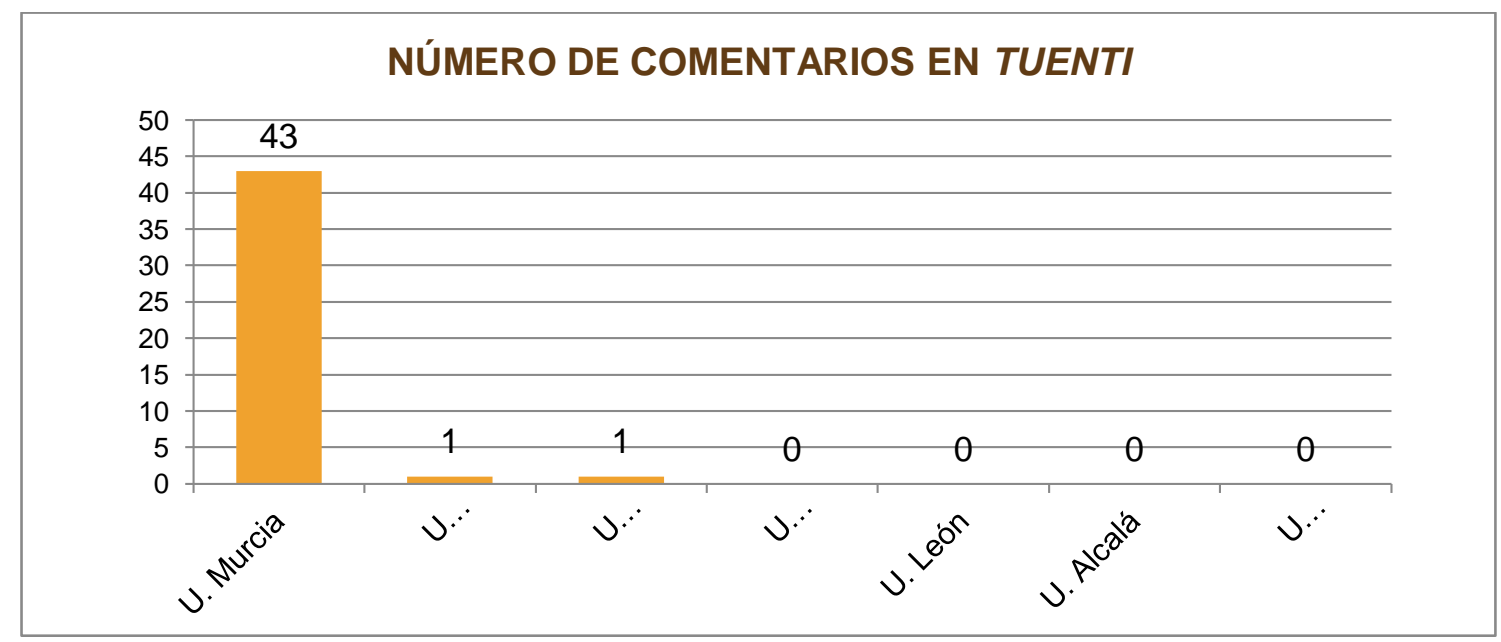

Figura 8 - Número de comentarios en Tuenti por cada una de las facultades que imparten titulaciones del ámbito de Información y Documentación. Fuente: Elaboración propia.

Observando finalmente los resultados de la red social $\underline{\text { Twitter }}$, la Facultad de Ciencias de la Comunicación de la Universidad Autónoma de Barcelona se sitúa en primera posición con 560 seguidores, seguida de la Escuela Técnica Superior de Ingeniería Informática de la Universidad Politécnica de Valencia con 478. La Facultad de Comunicación y Documentación de la Universidad de Granada, con sus 58 seguidores, es la que menos tiene (figura 9).

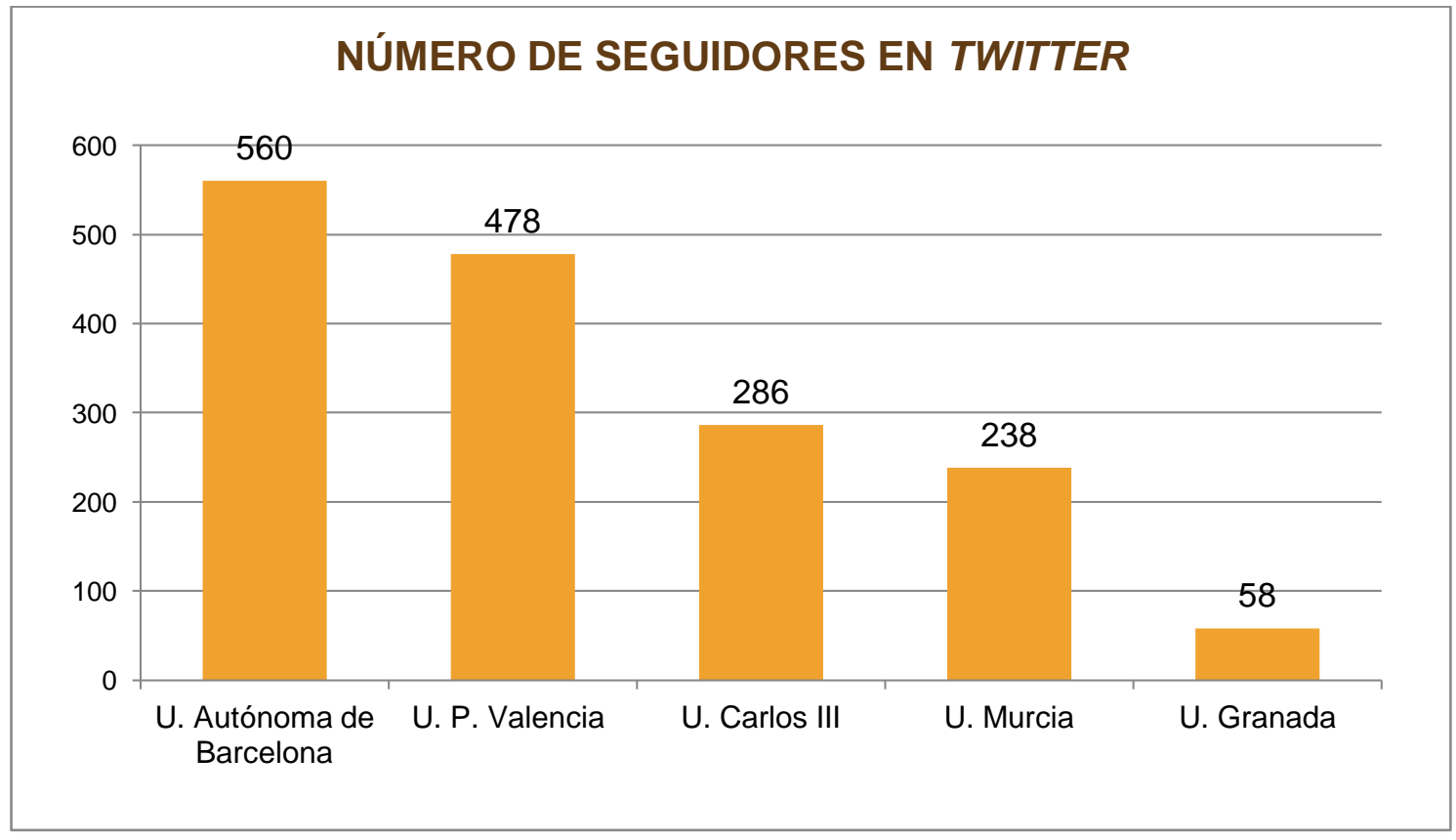

Figura 9 - Número de seguidores en Twitter por cada una de las facultades que imparten titulaciones del ámbito de Información y Documentación. Fuente: Elaboración propia. 
En relación al número de publicaciones (o de tweets), la Escuela Técnica Superior de Ingeniería Informática de la Universidad Politécnica de Valencia se sitúa en primera posición con 590 publicaciones, seguida de la Facultad de Ciencias de la Comunicación de la Universidad Autónoma de Barcelona con 358. Sin embargo, la Facultad de Comunicación y Documentación de la Universidad de Granada es la que menos publicaciones ha hecho (19) en esta red social (figura 10).

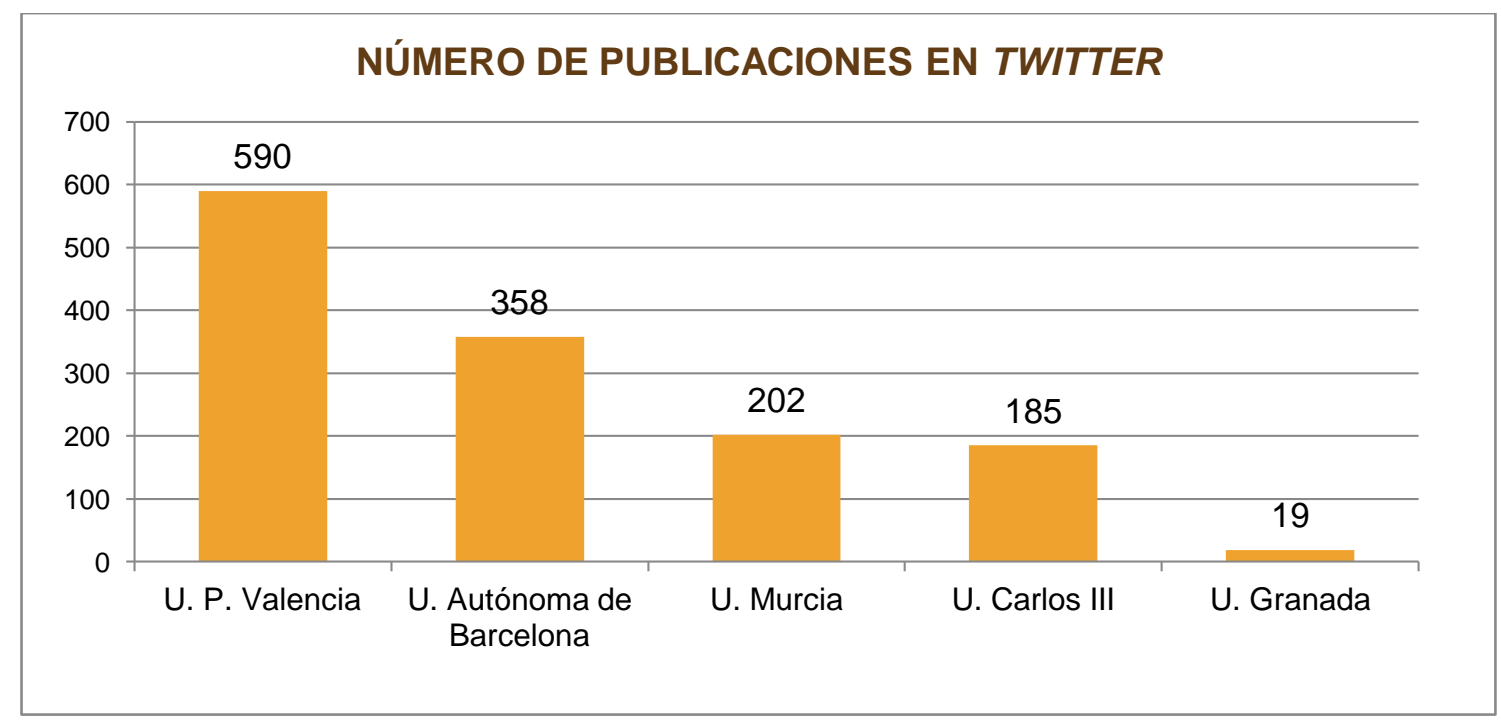

Figura 10 - Número de publicaciones en Twitter por cada una de las facultades que imparten titulaciones del ámbito de Información y Documentación. Fuente: Elaboración propia.

Finalmente, en referencia al número de comentarios realizados, en Twitter, no se tiene el concepto de comentario, ya que éstos se consideran tweets o publicaciones, y, que es, precisamente, lo que se acaba de analizar en los párrafos anteriores.

\section{Conclusiones}

En primer lugar, como se ha comprobado en este trabajo, las redes sociales están presentes en la sociedad día tras día, extendiendo su aplicación a diferentes ámbitos. Sus ventajas son múltiples, pero cabe destacar las siguientes: los servicios que ofrecen son, en su mayoría, gratuitos, y se adaptan a las necesidades de la comunidad a la que sirven. Atendiendo a la enseñanza, indicar que facilitan el contacto entre alumnos, docentes y asociaciones, organizaciones o colegios profesionales, constituyen el medio ideal para informar y difundir noticias, eventos u otras actividades, tanto administrativas como académicas. Además, posibilita la creación de grupos o páginas para los distintos cursos y titulaciones, consiguiendo una difusión selectiva de la información acorde con los usuarios finales de la misma y, en definitiva, consiguen mejorar las relaciones que se establecen dentro de la comunidad universitaria.

Teniendo en cuenta las ventajas de las redes sociales como medio de difusión del conocimiento, a través del análisis que se ha efectuado queda patente que alguna de las facultades o escuelas de documentación hacen un uso profuso de las mismas. Este es el caso de la Escuela Técnica Superior de Ingeniería Informática de la Universidad Politécnica de Valencia, que destaca en varios de los indicadores que se han estudiado sobre la red social Facebook. Sin embargo, en contraste con lo anterior, ninguna de los centros, de los dieciséis que componen la muestra, aparece en la red social Flickr. La Facultad de Comunicación y Documentación de la Universidad de Murcia es la que más destaca en varios de los indicadores de los que se han observado en la red social Tuenti. En cuanto a la aplicación social Twitter, sobresalen la Facultad de Ciencias de la Comunicación de la Universidad Autónoma de 
Barcelona y la Escuela Técnica Superior de Ingeniería Informática de la Universidad Politécnica de Valencia con unos resultados bastante igualados. La única diferencia reside en los indicadores analizados. Así, la primera de ellas tiene más usuarios registrados que la segunda, y, sin embargo, ésta última ha realizado muchas más publicaciones que la otra facultad.

En referencia a los centros que menor uso hacen de las redes sociales, como muestran los resultados, la Facultad de Humanidades de la Universidad de la Coruña y la Facultad de Educación, Traducción y Ciencias Humanas de la Universidad de Vich sólo están presentes en Facebook y, para cada uno de los indicadores estudiados, los valores son muy cercanos a cero, o, incluso varios de ellos son cero. Otra de las facultades con poca actividad en las herramientas sociales de las que se viene hablando ha sido la Facultad de Filosofía y Letras de la Universidad de Zaragoza, la cual está presente en Facebook y Tuenti, pero en unos niveles muy bajos.

Podemos aventurar que quizá, en algunos casos, la falta de utilización viene por una escasa, o nula, promoción de las redes sociales de las facultades en la comunidad universitaria. Si los miembros potenciales de ésta no tienen información acerca de su existencia, así como de las ventajas que proporcionan, es imposible que una aplicación 2.0 se desarrolle y crezca.

Incidiendo en las herramientas más utilizadas, el estudio muestra que Facebook es la más explotada y, por consiguiente, posee una mayor presencia en el conjunto de facultades y/o escuelas que imparten al menos alguna de las titulaciones del área de Información y Documentación (concretamente, en 12 de las 16). Asimismo, en todos los indicadores seleccionados (tanto en número de usuarios registrados, de publicaciones y de comentarios) se han obtenido mejores cifras.

No es extraño observar estos resultados, ya que esta red social proporciona numerosos servicios a los usuarios: grupos, páginas, listas de amigos, etc., en los que se puede incluir, además de texto, fotografías o vídeos, ficheros en cualquier formato, todos ellos útiles para apoyar el aprendizaje de los discentes. Además, según lo observado, aparentemente, sus creadores tratan de facilitar el manejo de la aplicación y de adaptarla al usuario final.

En el extremo opuesto se haya la aplicación Flickr que, como los resultados dejan observar, es la más infrautilizada por parte de las facultades. Pensamos que puede deberse al desconocimiento de las oportunidades que ofrece en materia de fotografías o vídeos o, también, por la "sombra" que les hacen los Sistemas de Gestión de Contenidos utilizados en los portales de las Universidades, los cuales poseen múltiples opciones y son capaces de almacenar este tipo de contenidos multimedia.

De todos modos, no es incompatible simultanear el uso de unas herramientas más "institucionales" con las redes sociales, ya que éstas últimas permiten dar a conocer nuestro centro de estudios a nivel mundial, acercando los contenidos a los usuarios por medio de las herramientas que más utilizan en su vida diaria.

Desde nuestro punto de vista, siempre es bueno difundir la información por todos los canales o medios disponibles, más si tenemos en cuenta, tal y como se expuso en la introducción, que el uso de las aplicaciones 2.0 está aumentando exponencialmente con el paso de los años.

Si nuestras facultades hacen un uso profuso de ellas, conseguirán aumentar su visibilidad y alcance, proporcionando una imagen actual a todos los alumnos, ya sean aquellos que están cursando una titulación o aquellos otros que vayan a iniciar sus estudios y quieran conocer, por ejemplo, las fechas clave para la preinscripción o matrícula de la misma.

Finalmente, quisiéramos indicar que las perspectivas son favorables y la presencia de las facultades de documentación de las universidades españolas en las redes sociales es alta. Únicamente, 2 de las 16 no tenían presencia alguna en estos medios cuando se llevó a cabo el estudio. Esperamos que se continúe en esa línea y que los usuarios, tanto profesores como alumnos, tanto reales como potenciales, aumenten su participación en ellas, promuevan su uso, y difundan su utilidad en los entornos educativos como medio para el desarrollo de las capacidades y competencias, así como herramienta para el aprendizaje de cualquier disciplina. 


\section{Bibliografía}

ÁLVAREZ, G., y LÓPEZ, M. (2013). Análisis del uso de Facebook en el ámbito universitario desde la perspectiva del aprendizaje colaborativo a través de la computadora. Edutec-e. Revista Electrónica de Tecnología Educativa, 43. Recuperado de http://goo.gl/FLnxl

ARANBURU, J. J. (2011). Redes sociales y museos participativos: la irrupción de las tecnologías 2.0 en la sociedad y su aplicación en los museos a través del caso Arazi. En A. Ibáñez Etxeberria (ed.). Museos, redes sociales y tecnología 2.0. Museums, social media and 2.0 technology (pp. 120-121). Guipuzkoa, Servicio Editorial de la Universidad del País Vasco. Recuperado de http://goo.gl/QzTtz

Ayuntamiento de Algeciras. (2012). Portal Web del Ciudadano del Ayuntamiento de Algeciras. Recuperado de http://www.algeciras.es/redsocial//

CALDEVILLA DOMínGUEZ, D. (2010). Las Redes Sociales. Tipología, uso y consumo de las redes 2.0 en la sociedad digital actual. Documentación de las ciencias de la información, 33, 45-68. Recuperado de http://goo.gl/wo2mP

CASTELLÓ MARTíNEZ, A. (2010). Una nueva figura profesional: el Community Manager. Pangea. Revista de la Red Académica Iberoamericana de Comunicación, 1, 75-76.

CELAYA, J. (2008). La empresa en la Web 2.0. Madrid: Gestión 2000.

CHAÍN NAVARRO, C., MARTíNEZ SOLÍS, L., y SÁNCHEZ BAENA, J. J. (2008). Motivar desde la innovación en la enseñanza universitaria: el "blog calidad". RED. Revista de Educación a Distancia, 21. Recuperado de http://www.um.es/ead/red/21/chain.pdf

Cocktail Analysis, The. (2011). Informe de resultados. Observatorio de redes sociales: tercera oleada. Recuperado de http://g00.gl/5adZ7

Discapnet. (2010). Accesibilidad de Plataformas de Redes Sociales Recuperado de http://goo.gl/zsV27

Dosdoce. (2010). Chuleta de las redes sociales en España. Recuperado de http://goo.gl/9DQ1r

EGAÑA, T., BIDEGAIN, E., y ZUBEROGOITIA, A. (2013). ¿Cómo buscan información académica en Internet los estudiantes universitarios? Lo que dicen los estudiantes y sus profesores. Edutec-e. Revista Electrónica de Tecnología Educativa, 43. Recuperado de http://goo.gl/1XXuo

ESTEVE MON, F. M. y GISBERT CERVET, M. (2011). El Nuevo paradigma de aprendizaje y nuevas tecnologías. REDU - Revista de Docencia Universitaria, 9(3). Recuperado de http://www.red-u.net/redu/index.php/REDU/article/view/301

Gabinete de Comunicación de la Universidad de Extremadura (2012). La Facultad de Biblioteconomía cambia de nombre. Recuperado de http://goo.gl/BaoCB

Levante-EMV. (2010). La 'dipu' debuta en seis redes sociales y estrena 'blog'. Levante-emv.com: el mercantil valenciano. Recuperado de http://goo.gl//hAhm

LÓPEZ MENESES, E., LLORENT GARCÍA, V. J., y FERNÁNDEZ MÁRQUEZ, E. (2013). Experiencia universitaria sobre las funciones del educador/a social con tecnologías 2.0. Edutec-e. Revista Electrónica de Tecnología Educativa, 43. Recuperado de http://g00.gl/i3O7F

MARTÍNEZ SOLÍS, L. (2012). Conocimiento compartido acerca de familias hispanas: las wikis como herramientas para la difusión de genealogías a través de Internet. En XV Congreso Internacional de la Asociación Española de Americanistas. América en la Memoria: Conmemoraciones y Reencuentros.

MARTÍNEZ SOLÍS, L., CHAÍN NAVARRO, C., y SÁNCHEZ BAENA, J. J. (2011). Continuar aprendiendo sin coincidir ni en el espacio ni en el tiempo: propuesta para la asignatura "Archivística, Documentación y Tecnología" del Posgrado en Historia Naval. En Congreso Internacional de Innovación Docente.

MARTÍNEZ SOLÍS, L., CHAÍN NAVARRO, C., y SÁNCHEZ BAENA, J. J. (2011). Naval documentary heritage and their diffusion on Internet: towards a big virtual archive of Mare Nostrum. En 3rd EMUNI Research Souk: The Euro-Mediterranean StudentResearch Multi-conference (pp. 721-726). Recuperado de http://qoo.gl/aQSAz

MARTÍNEZ SOLÍS, L., CHAÍN NAVARRO, C., y SÁNCHEZ BAENA, J. J. (2012). Genealogía Naval Wiki: generation and dissemination of knowledge shared over the Internet. En $4^{\text {th }}$ EMUNI Research Souk. The Euro-Mediterranean Student-Research Multi-conference (pp. 295-304). Recuperado de http://goo.gl/250fa

RADILLO, G. (2010). Soy community manager y me pagan por twittear. Recuperado de http://goo.gl/3fmtM. Citado por COBOS, T. L. (2011). Y surge el community manager. Razón y palabra. Primera revista electrónica en América Latina Especializada en Comunicación, 75. 
Tati. (2010). ¿Cuál es la mejor red social? Vote por su favorita. elEconomista.es: la red social de los inversores, directivos y empresarios. Recuperado de http://goo.gl/K6yaQ

Techsip. (2012). A History of the Business of Social Media. Recuperado de http://goo.gl/cbg0q

VILLANUEVA MATEO, J. C. (2012). Fondos sonoros en los repositorios digitales académicos y de investigación. Tejuelo. Revista de ANABAD, 12. Recuperado de http://www.anabadmurcia.org/ojs/index.php/tejuelo/article/view/75/77

\title{
Datos de los autores
}

\author{
Juan Carlos Villanueva Mateo
}

Diplomado en Biblioteconomía y Documentación, obteniendo el Premio Extraordinario Fin de Carrera y mención honorífica en los Premios Nacionales, Graduado en Información y Documentación y Magíster en Historia y Patrimonio Naval por la Universidad de Murcia.

juancarlos.villanueva@um.es

Lorena Martínez Solís

Licenciada en Documentación y Doctora Cum Laude por la Universidad de Murcia.

loremart@um.es

$\begin{array}{ll}\text { Recibido-Received } & : 2013-10-14 \\ \text { Aceptado-Accepted } & : 2013-12-30\end{array}$

\section{Notas}

1 Este trabajo es uno de los resultados del proyecto "Argos II" (11936/PHCS/09), financiado por la Fundación Séneca.

${ }^{2}$ Blog de la Cátedra de Historia Naval: http://pinake.wordpress.com/; Facebook de la Cátedra de Historia Naval: https://www.facebook.com/catedranaval

3 "En ellas los usuarios puedes enviar y votar noticias, como en: Menéame (www.meneame.net) o Culturízame (www.culturizame.net)". (Citado por Castelló Martínez, 2010, p. 76).

4 "Los marcadores sociales, los sistemas de etiquetado y los de filtrado social permiten almacenar, clasificar y compartir enlaces a contenidos de Internet de forma sencilla. Todas ellas se basan en las llamadas tags o etiquetas, palabras asociadas a una página web, foto o vídeo que permiten identificar el contenido y acotar su búsqueda, estableciendo incluso relaciones entre las personas que las emplean (Del.icio.us para páginas web y Flickr, para fotos, son ejemplos de marcadores sociales). Ejemplo de su uso con fines corporativos es la galería con que cuenta LG en Flickr (www.flickr.com/photos/lgblog)". (Citado por Castelló Martínez, 2010, p. 76).

5 "Permite a los usuarios suscribirse a los contenidos de cuentas fuentes deseen, de tal forma que tengan en un solo lugar, conocido como agregador, todo aquello que les interese. La fuente de sindicación más aceptada es RSS (Really Simple Sindication - Rich Site Summary). A la sindicación de archivos de sonido se le conoce como podcasting, término formado por el acrónimo de publico $n$ demand y la palabra broadcasting (retransmisión bajo demanda)". (Citado por Castelló Martínez, 2010, p. 76).

6 "Herramientas de comunicación que permiten a los usuarios enviar mensajes de texto con una longitud determinada de caracteres (en general, en torno a 140 caracteres) de forma instantánea y gratuita, como Twitter, Jaiku, Pownce o YouAre. Con sus cerca de dos millones y medio de usuarios, Twitter se ha convertido en el líder indiscutible del microblogging". (Celaya, 2008. Citado por Castelló Martínez, 2010, p. 76).

7 "Las comunicaciones personalizadas, interacciones y experiencias de marca que pueden ofrecerse en los medios sociales facilita la creación de comunidades en torno a la marca o imagen de la organización. Con estas nuevas 
herramientas, las instituciones pueden relacionarse con los usuarios, aportarles valor y, por lo tanto, generar branding social”. (Castelló Martínez, 2010, p. 83).

${ }^{8}$ La Web 2.0 supone la superación de una previa, la 1.0. Dentro de esta primera etapa se enmarcan las páginas web convencionales en las que el usuario es un receptor pasivo de información. En la 2.0, sin embargo, se incluyen aplicaciones como los blogs, las wikis, o perfiles en redes sociales, entre otras herramientas, en las que el individuo que está al otro lado de la pantalla puede interactuar con lo expuesto a través de Internet, convirtiéndose de este modo en un editor-productor activo de contenido digital.

${ }^{9}$ Recuperado de http://edutec.rediris.es/Revelec2/Revelec43/

10 Recuperado de http://goo.gl/Pfd1X

11 A partir del 26 de abril de 2012 pasa a denominarse Facultad de Ciencias de la Documentación y la Comunicación. (Gabinete de Comunicación de la Universidad de Extremadura, 2012).

12 Alexa.com es una empresa fundada en 1996, adquirida por Amazon.com en 1999, y asociada con Google desde 2002. Alexa rastrea masivamente la web y, mediante una serie de complejos procesos y tras analizar millones de datos, calcula el tráfico de los sitios de Internet y los clasifica en atención a su importancia, determinando su posición en el ranking mundial. Más información en http://goo.gl/OtxaR

${ }^{13}$ Para realizar su mapa de redes, los integrantes de la citada web han analizado de forma básica en qué medida las diferentes herramientas de la web social se pueden emplear en varios ámbitos de la comunicación: gestión de reputación digital, comunicación corporativa, comunicación de productos y eventos, visibilidad, prevención de crisis, atención al cliente, gestión de conocimiento, comunicación interna y captación de talento. En cada caso, han valorado tanto su eficacia como sus principales características con un sencillo código de colores y una breve explicación. Dosdoce. Chuleta de las redes sociales en España [en línea]. [Consulta: 03-05-2012]. Disponible en http://g0o.gl/9DQ1r.

${ }^{14}$ El número de usuarios registrados es un factor clave para determinar si una institución está más o menos presente en una red social, indicando, en mayor medida, el grado de participación de éstos con la institución y la mayor o menor presencia de la institución en la red social.

15 El número de noticias publicadas por los usuarios en la red social indica, en mayor medida, el grado de participación de éstos con la institución, y, por otro lado, el número de noticias publicadas por la institución, indicará el uso que le da dicha institución a la red social como medio de difusión o promoción de sus actividades.

${ }^{16}$ Los comentarios, marcas y/o retweets realizados indican el uso que los usuarios y/o la propia institución le da a la red social, y por tanto, la presencia de la institución en la misma.

${ }^{17}$ Aunque por motivos de estilo tan sólo aparece el nombre de la Universidad en este y en los siguientes gráficos, se recuerda que siempre se está haciendo referencia a la Facultad en la que se imparte alguna de las carreras relacionadas con la Información y Documentación de esas universidades. Si se quiere recordar el nombre de la Facultad de la Universidad en cuestión, puede consultarse la tabla 1 del presente trabajo.

\section{$(\mathrm{cc}) \mathrm{BY}$}

This work is licensed under a Creative Commons Attribution 4.0

United States License.

\section{UILIS D-Surk}

This journal is published by the University Library System of the University of Pittsburgh as part of its D-Scribe Digital Publishing Program and is cosponsored by the University of Pittsburgh Press. 